\title{
Systematic review of raloxifene in postmenopausal Japanese women with osteoporosis or low bone mass (osteopenia)
}

This article was published in the following Dove Press journal:

Clinical Interventions in Aging

5 November 2014

Number of times this article has been viewed

\author{
Saeko Fujiwara' \\ Etsuro Hamaya ${ }^{2}$ \\ Masayo Sato ${ }^{2}$ \\ Peita Graham-Clarke ${ }^{3}$ \\ Jennifer A Flynn² \\ Russel Burge \\ 'Hiroshima Atomic Bomb Casualty \\ Council, Hiroshima, Japan; ${ }^{2}$ Lilly \\ Research Laboratories Japan, \\ Eli Lilly Japan K.K., Kobe, Japan; \\ ${ }^{3}$ Global Health Outcomes, Eli Lilly \\ Australia, Sydney, NSW, Australia; \\ ${ }^{4}$ Global Health Outcomes, Eli Lilly and \\ Company, Indianapolis, IN, USA
}

Correspondence: Masayo Sato

Lilly Research Laboratories Japan,

Eli Lilly Japan K.K., 7-I-5 Isogami Dori,

Chuo-ku, Kobe, Hyogo, Japan, 65I-0086

Tel +81782429317

Fax +81782429526

Email sato_masayo@lilly.com
Purpose: To systematically review the literature describing the efficacy, effectiveness, and safety of raloxifene for postmenopausal Japanese women with osteoporosis or low bone mass (osteopenia).

Materials and methods: Medline via PubMed and Embase was systematically searched using prespecified terms. Retrieved publications were screened and included if they described randomized controlled trials or observational studies of postmenopausal Japanese women with osteoporosis or osteopenia treated with raloxifene and reported one or more outcome measures (change in bone mineral density [BMD]; fracture incidence; change in bone-turnover markers, hip structural geometry, or blood-lipid profile; occurrence of adverse events; and change in quality of life or pain). Excluded publications were case studies, editorials, letters to the editor, narrative reviews, or publications from non-peer-reviewed journals; multidrug, multicountry, or multidisease studies with no drug-, country-, or disease-level analysis; or studies of participants on dialysis.

Results: Of the 292 publications retrieved, 15 publications (seven randomized controlled trials, eight observational studies) were included for review. Overall findings were statistically significant increases in BMD of the lumbar spine (nine publications), but not the hip region (eight publications), a low incidence of vertebral fracture (three publications), decreases in markers of bone turnover (eleven publications), improved hip structural geometry (two publications), improved blood-lipid profiles (five publications), a low incidence of hot flushes, leg cramps, venous thromboembolism, and stroke (12 publications), and improved quality of life and pain relief (one publication).

Conclusion: Findings support raloxifene for reducing vertebral fracture risk by improving BMD and reducing bone turnover in postmenopausal Japanese women with osteoporosis or osteopenia. Careful consideration of fracture risk and the risk-benefit profile of antiosteoporosis medications is required when managing patients with osteoporosis.

Keywords: bone density, fractures, osteoporotic, Japan, osteoporosis, raloxifene

\section{Introduction}

Osteoporosis is a major health problem worldwide that is "characterized by low bone mass and microarchitectural deterioration of bone tissue, with a consequent increase in bone fragility and susceptibility to fractures". ${ }^{1}$ In Japan, population-based estimates using 2005 data and no age cutoffs suggest that osteoporosis affects between 6.4 million and 11 million people, and that the incidence of osteoporosis increases with age and is significantly greater in women than men. ${ }^{2}$ Given that Japanese people have the world's longest life expectancy from birth (currently at 83.7 years for 2010-2015) ${ }^{3}$ and Japan's rapidly increasing aged population, ${ }^{4}$ there is a clear need to reduce the burden of osteoporosis in the coming years. 
Fracture is the most serious consequence of osteoporosis. This is primarily because women with osteoporosis have marked deterioration in bone mineral density (BMD) and bone architecture, which results in deterioration in bone strength. ${ }^{5}$ Of the types of osteoporotic fractures, vertebral fractures are of great concern, because of the risk of subsequent vertebral fractures and the resulting "vertebral fracture cascade", ${ }^{6}$ the increased risk of nonvertebral fractures following vertebral fractures, ${ }^{7,8}$ and the considerable effect vertebral fractures have on pain, health-related quality of life, and mortality rate. ${ }^{9-14}$ The impact of vertebral fractures is particularly important for Japanese women, because findings in population-based or longitudinal studies that used similar morphometric methods to assess the incidence of vertebral fracture have shown a higher incidence of vertebral fractures in Japanese women than Caucasian women. ${ }^{15-17}$ Hip fractures resulting from osteoporosis are also a significant burden. In Japan, hip-fracture incidence is expected to increase $68 \%$ from 2012 to 2040, with an average hospital cost of US\$27,599 for surgical treatment. ${ }^{18}$

In Japan, therapeutic treatments recommended for osteoporosis include bisphosphonates (eg, risedronate, alendronate), selective estrogen-receptor modulators (eg, raloxifene, bazedoxifene), active vitamin $\mathrm{D}_{3}$ derivatives (eg, alfacalcidol, eldecalcitol), and recombinant parathyroid hormone. ${ }^{19}$ Bisphosphonates are the most familiar and well-studied of these treatments, ${ }^{19,20}$ with proven efficacy for vertebral fracture reduction in Japanese patients..$^{21}$ Of the other treatments, raloxifene, a nonsteroidal benzothiophene derivative of the selective estrogen receptor-modulator class, has been used to treat postmenopausal osteoporosis in Japan since May 2004 (60 mg tablets). ${ }^{19}$ Raloxifene is a suitable therapy for the treatment of postmenopausal osteoporosis, because the estrogen-like actions of raloxifene in bone averts the imbalance in bone turnover (excess resorption versus formation) caused by postmenopausal estrogen deficiency. In addition, the estrogen-like actions of raloxifene are tissue-specific, because raloxifene does not stimulate mammary or uterine endometrial tissue. ${ }^{22}$ Compared with placebo, raloxifene has been shown to reduce the relative risk of vertebral fractures by up to $69 \%$ in postmenopausal Caucasian women with osteoporosis after 3 years of treatment. ${ }^{23}$ Additional findings for raloxifene indicate increases in lumbar spine $\mathrm{BMD}^{22}$ and in terms of bone quality, improvements in hip cortical geometry, ${ }^{24,25}$ and collagen quality by reducing nonenzymatic collagen crosslinks, ${ }^{26}$ and the maintenance of heterogeneous mineralization in bone. ${ }^{27}$ Although findings from a post hoc analysis of data from two independent studies indicated that postmenopausal
Japanese and Chinese women treated with raloxifene had a lower incidence of vertebral fractures than those treated with placebo, ${ }^{28}$ the available data describing the effect of raloxifene treatment in postmenopausal Japanese women have not been adequately synthesized. Synthesis and evaluation of these data may provide valuable information for Japanese physicians treating postmenopausal women with osteoporosis.

To evaluate the existing evidence for postmenopausal Japanese women with osteoporosis or low bone mass (osteopenia) treated with raloxifene, we performed a systematic review of the literature. The objective of this review was to examine the efficacy, effectiveness, and safety findings from clinical trials and observational studies of raloxifene and to provide clinical insight into the usefulness of raloxifene for preventing or reducing the risk of subsequent vertebral and nonvertebral fractures in Japan.

\section{Materials and methods \\ Search strategy}

A search for relevant publications was done on May 28, 2013 using the database Medline via PubMed and Embase. The search terms were Japan (Medical Subject Headings [MeSH], Emtree), raloxifene (MeSH, Emtree), Evista, osteoporosis (MeSH, Emtree), fracture (Emtree), fracture*, and bone density (MeSH, Emtree). Search terms were combined using the Boolean operators OR and AND to give the following strategy: Japan AND (raloxifene OR Evista) AND (osteoporosis OR [fracture OR fracture*] OR bone density). The search limits were human species only and publication date from January 1, 1980 onwards.

\section{Study selection}

Publications identified in Medline via PubMed and Embase were collated using Endnote X5 (Thomson Reuters, New York, NY, USA). Duplicate publications were discarded, and the remaining publications were screened using prespecified inclusion and exclusion criteria. The title and abstract of each publication were screened initially; the full text of a publication was screened only if screening of the title and abstract was inconclusive. Publications describing randomized controlled clinical trials and observational studies (prospective and retrospective) of postmenopausal women with osteoporosis or osteopenia receiving raloxifene treatment were included if they reported one or more outcome measures. Outcome measures were change in BMD of the lumbar spine, femoral neck, total hip, total neck, or other areas within the hip region; incidence of new vertebral fracture or nonvertebral fracture; change in biochemical markers 
of bone turnover, hip structural geometry, or blood-lipid profile; occurrence of adverse events (AEs; type, incidence, and severity), in particular venous thromboembolism (VTE), cardiovascular events, stroke, vaginal bleeding, or hot flush; effect on coagulation parameters or breast, uterus, ovary, or reproductive tissues; and change in quality of life or pain.

Publications were excluded if they were case studies, editorials, letters to the editor, narrative reviews, or published in a non-peer-reviewed journal; were multidrug studies that did not include a subanalysis of raloxifene; were multicountry studies that did not include a subanalysis of Japanese participants; were multidisease studies that did not include a subanalysis of participants with osteoporosis or osteopenia; or if participants were on dialysis. The bibliographies of systematic reviews were screened for other potentially relevant publications.

\section{Data extraction and analysis}

Data extraction was conducted by one person, and the extracted data were reviewed by all authors. Data extracted were study and participant characteristics (study design, number and mean age of participants, therapy and dose, study duration [ie, number of weeks], disease definition, study objective), and findings for BMD of the lumbar spine, femoral neck, total hip, total neck, or other areas within the hip region (percentage change in BMD from baseline to 52 weeks or BMD at baseline and at 52 weeks), vertebral and nonvertebral fracture incidence, biochemical markers for bone turnover (percentage change in concentration from baseline to 52 weeks or concentration at baseline and at 52 weeks), hip structural geometry parameters (percentage change in parameters from baseline to 52 weeks), blood-lipid profile (percentage change in concentration from baseline to 52 weeks or concentration at baseline and at 52 weeks), AEs (type, incidence, and severity; incidence of VTE, cardiovascular events, stroke, vaginal bleeding, or hot flush) and quality of life and pain (mean change in scores from baseline to 24 weeks).

\section{Results}

\section{Literature-search results}

A total of 292 abstracts were retrieved from the search of PubMed and Embase (Figure 1). Duplicate publications were discarded $(\mathrm{n}=65)$, the remaining 227 abstracts screened, and 26 publications selected for full-text review. The main reasons for exclusion were no relevant outcomes reported, raloxifene not included, or study not conducted in humans (Figure 1). The remaining 15 publications were included for review.

\section{Study and participant characteristics}

Of the 15 publications included for review, there were seven randomized controlled trials ${ }^{29-35}$ reporting evidence for efficacy and eight observational studies ${ }^{24,36-42}$ reporting evidence of effectiveness (Table 1). Evidence of safety was reported in $12^{29-33,35-38,40-42}$ of the 15 publications. The method of randomization and allocation (eg, randomly generated treatment codes, random self-drawing of prepared sealed envelopes) was described in four ${ }^{29,32,33,35}$ of the seven randomized controlled trials. Only the double-blind placebocontrolled trial ${ }^{35}$ and an open-label randomized controlled trial ${ }^{30}$ described whether randomization and allocation were blinded. The number of participants enrolled varied from 39 in one randomized controlled trial ${ }^{30}$ to 7,557 in two postmarketing surveillance observational studies. ${ }^{40,41}$ The mean age of participants ranged from 63 to 80 years (Table 1). On average, most participants had undergone menopause at 50 years of age (data not shown). Most publications (14 of 15) assessed the effects of raloxifene for a minimum of 52 weeks (Table 1). A definition for osteoporosis and osteopenia was reported in 14 of the 15 publications, with most publications $(\mathrm{n}=11)$ defining osteoporosis and osteopenia according to the Japanese diagnostic criteria year 2000 revision $^{43}$ (Table 1).

\section{BMD}

Findings for BMD were reported in eleven of the 15 publications, and included BMD of the lumbar spine (nine publications), ${ }^{29,31-33,35-38,40}$ of the femoral neck, total hip, or total neck (six publications), ${ }^{29,32,33,36-38}$ or of other regions in the hip (five publications). ${ }^{24,33,36,38,39}$ Findings were reported as the percentage change in BMD from baseline to 52 weeks or BMD at baseline and at 52 weeks in all publications. There were three longer-term studies reporting BMD at 104 weeks $^{24,32,40}$ and at 156 weeks. ${ }^{40}$

After 52 weeks of treatment with raloxifene $60 \mathrm{mg} / \mathrm{day}$, lumbar spine BMD increased significantly from baseline in all nine publications reporting findings for lumbar spine $\mathrm{BMD}$, including the randomized placebo-controlled trial ${ }^{35}$ of raloxifene 60 or $120 \mathrm{mg} /$ day (Table 2). In the randomized comparative trials, the increase in lumbar spine BMD for raloxifene was less than that for alendronate $(P<0.01),{ }^{31}$ more than that for alfacalcidol, ${ }^{29,32}$ and less than ${ }^{32}$ or more $\operatorname{than}^{29,33}$ that for combination treatment with raloxifene and alfacalcidol (Table 2).

Compared with lumbar spine BMD, the effect of raloxifene $60 \mathrm{mg} /$ day on BMD in the femoral neck, total hip, or total neck (Table 2) or other regions of the hip (data not shown) was not consistent after 52 weeks of treatment. 


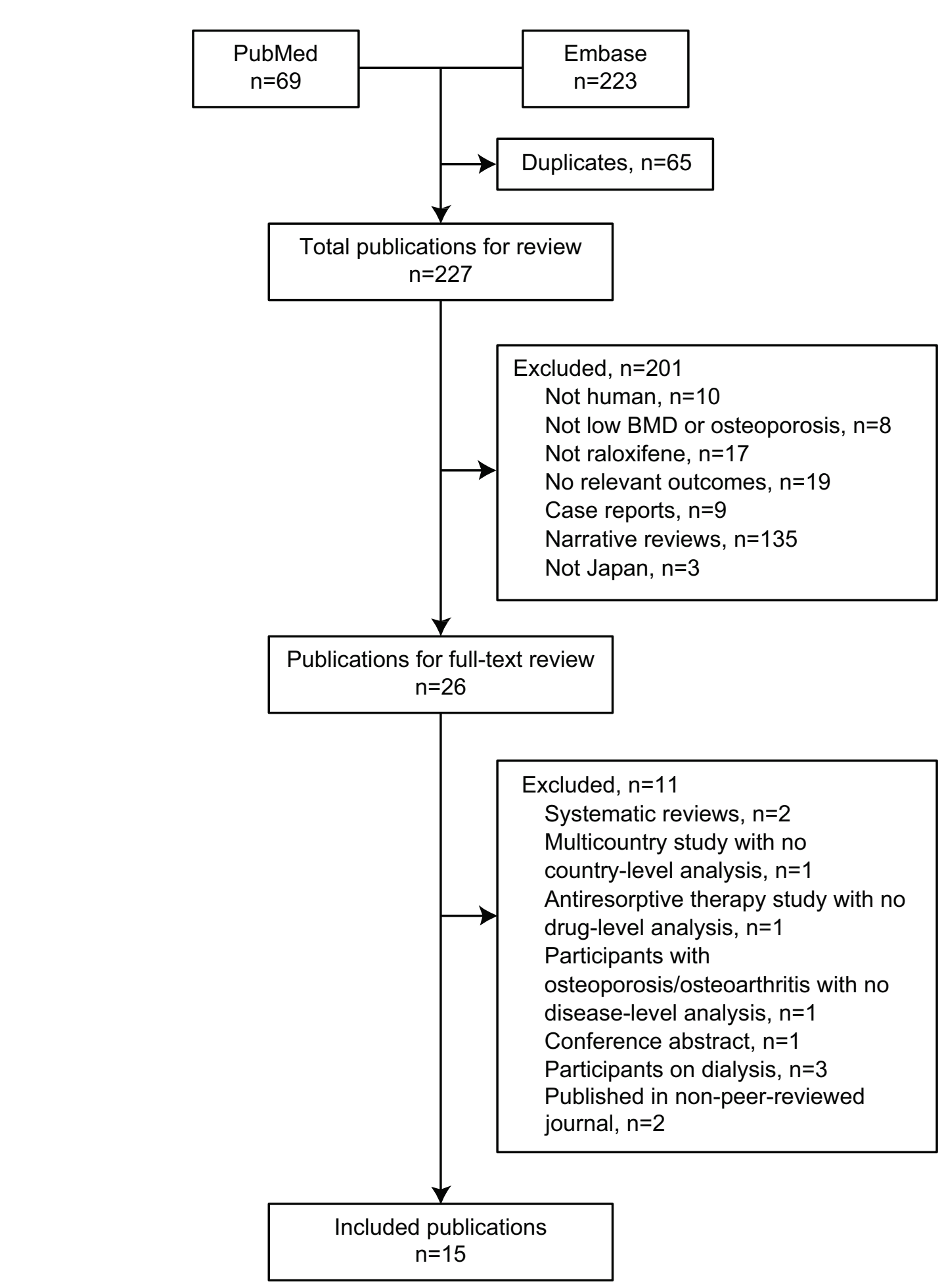

Figure I Flow diagram of literature-search results. Databases were Medline via PubMed and Embase. Searches were limited to human species and publications from I980 onwards. Abbreviation: BMD, bone mineral density.

In the eight publications $\mathrm{s}^{24,29,32,33,36-39}$ that reported findings for BMD in the femoral neck, total hip, total neck, or other regions of the hip, BMD increased, remained the same, or decreased; few of the increases in BMD were statistically significant.

\section{Fracture incidence}

Fracture incidence (vertebral or nonvertebral) was reported in three of the 15 publications, including publications from two randomized controlled trials $\mathrm{s}^{31,35}$ and one observational study.$^{40}$ However, only the observational study, which was a 


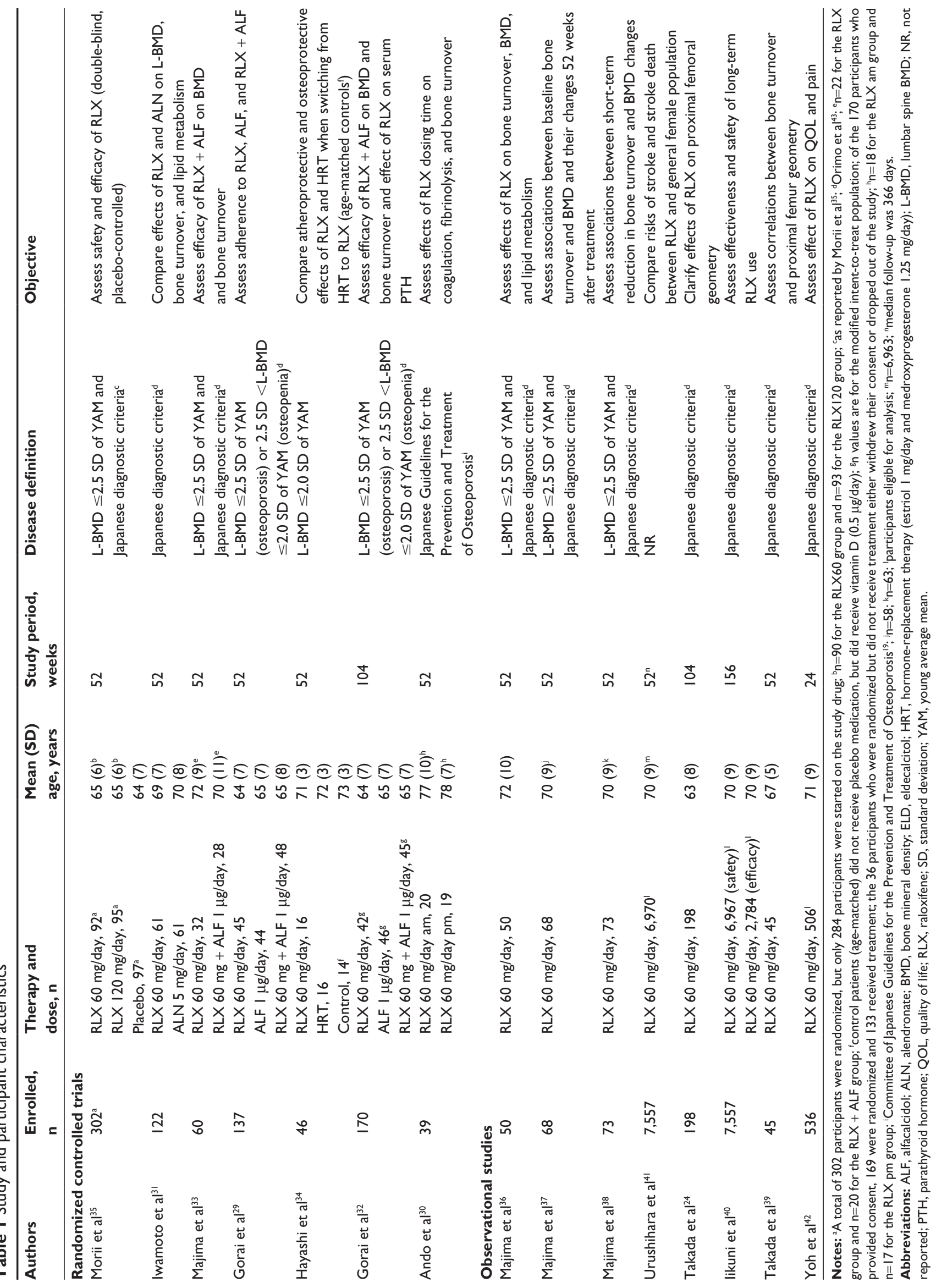


Table 2 Studies reporting mean (SD) percentage change in bone mineral density or mean (SD) bone mineral density $\left(\mathrm{g} / \mathrm{cm}^{2}\right)$ of the lumbar spine, femoral neck, total hip, or total neck after 52 weeks of RLX treatment ${ }^{\mathrm{a}}$

\begin{tabular}{|c|c|c|c|c|c|}
\hline Authors & Therapy & $\begin{array}{l}\text { Lumbar spine } \\
\% \text { or } \mathbf{g} / \mathrm{cm}^{2}\end{array}$ & $\begin{array}{l}\text { Femoral neck } \\
\% \text { or } \mathrm{g} / \mathrm{cm}^{2}\end{array}$ & $\begin{array}{l}\text { Total hip } \\
\% \text { or } \mathbf{g} / \mathbf{c m}^{2}\end{array}$ & $\begin{array}{l}\text { Total neck } \\
\% \text { or } \mathbf{g} / \mathrm{cm}^{2}\end{array}$ \\
\hline \multicolumn{6}{|c|}{ Randomized controlled trials } \\
\hline Morii et $\mathrm{al}^{35}$ & $\operatorname{RLX}$ & $+2.9(\mathrm{NR}) * * *, \mathrm{~b}$ & NM & NM & NM \\
\hline \multirow[t]{2}{*}{ Iwamoto et a $\left.\right|^{31}$} & RLX & $+2.4(\mathrm{NR})^{* *}$ & NM & NM & NM \\
\hline & ALN & $+8.0(\mathrm{NR})^{* *}$ & NM & NM & NM \\
\hline \multirow[t]{2}{*}{ Majima et $\mathrm{a}^{33}$} & $\mathrm{RLX}$ & $+6.3(5.8)^{* *}$ & $+0.8(6.3)$ & NM & $+2.1(5.3)$ \\
\hline & $\mathrm{RLX}+\mathrm{ALF}$ & $+4.9(7.7)^{* *}$ & $+3.0(17.4)$ & NM & $+1.8(7.9)$ \\
\hline \multirow[t]{3}{*}{ Gorai et $\mathrm{a}^{29}$} & $\mathrm{RLX}$ & $+3.0(\mathrm{NR})^{*}$ & NM & NR (NR) & NM \\
\hline & ALF & +0.7 (NR) & NM & $N R(N R)$ & NM \\
\hline & $\mathrm{RLX}+\mathrm{ALF}$ & $+4.6(\mathrm{NR})^{*}$ & NM & +2.0 (NR) & NM \\
\hline \multirow[t]{3}{*}{ Gorai et al ${ }^{32}$} & RLX & $+2.9(4.3)^{* *}$ & NM & $+1.6(3.5)^{*}$ & NM \\
\hline & ALF & $-0.3(4.4)$ & NM & $-0.1(3.8)$ & NM \\
\hline & $R L X+A L F$ & $+4.1(3.5)^{* * *}$ & NM & $+1.2(4.1)$ & NM \\
\hline \multicolumn{6}{|c|}{ Observational studies } \\
\hline Majima et $\mathrm{al}^{36}$ & RLX & $0.67(0.14), 0.72(0.13)^{* *}$ & $0.54(0.10), 0.56(0.10)$ & NM & $0.60(0.12), 0.61(0.13)$ \\
\hline Majima et $\mathrm{al}^{37}$ & RLX & $0.67(0.12), 0.70(0.12)^{* *}$ & $0.55(0.10), 0.55(0.10)$ & NM & NM \\
\hline Majima et $\mathrm{al}^{38}$ & RLX & $0.67(0.12), 0.70(0.12)^{* *}$ & $0.55(0.09), 0.55(0.09)$ & NM & $0.60(0.1 \mathrm{I}), 0.6 \mathrm{I}(0.12)$ \\
\hline likuni et $\mathrm{al}^{40}$ & RLX & $+2.9(\mathrm{NR}) * * *$ & NM & NM & NM \\
\hline
\end{tabular}

Notes: $* P<0.05, * * P<0.01$, and $* * * P<0.001$ indicate significant differences from baseline; ${ }^{\text {ad }}$ data from two studies reporting bone mineral density (BMD) findings were not included in this table because BMD findings were of other regions in the hip; ${ }^{24,39}$ b patients received either $\mathrm{RLX} 60 \mathrm{mg} / \mathrm{day}$ or RLX $120 \mathrm{mg} / \mathrm{day}$, $\mathrm{n}=183$.

Abbreviations: ALF, alfacalcidol; ALN, alendronate; NM, not measured; NR, not reported; RLX, raloxifene; SD, standard deviation.

postmarketing surveillance study, was sufficiently powered to detect the incidence of vertebral fractures. ${ }^{40}$ Findings from this study suggested that after 36 months of treatment with raloxifene, the incidence of new clinical vertebral and nonvertebral fractures in postmenopausal women is low. Of the 6,967 participants, $36(0.5 \%)$ reported new clinical vertebral fractures and $52(0.7 \%)$ reported new clinical nonvertebral fractures.$^{40}$ Nearly half of these participants had prevalent fractures: 17 of the 36 participants (47\%) with new clinical vertebral fractures and 19 of the 52 participants (37\%) with new clinical nonvertebral fractures.

In a smaller randomized placebo-controlled study, few postmenopausal women taking raloxifene $(60 \mathrm{mg}$ /day or $120 \mathrm{mg} /$ day $)$ had a new vertebral fracture $(0.05 \%$, one of 183 , versus placebo $2 \%$, two of 97 ) or a new nonvertebral fracture $(0.05 \%$, one of 183 , versus placebo $4 \%$, four of 97$)$ after 52 weeks of treatment. ${ }^{35}$ In addition, findings from another randomized study suggested that the incidence of vertebral fractures was not significantly different between postmenopausal women taking raloxifene $(13.1 \%, \mathrm{n}=61)$ and alendronate $(14.0 \%, \mathrm{n}=61){ }^{31}$

\section{Biochemical markers of bone turnover}

Findings for biochemical markers of bone turnover were reported in eleven of the 15 publications: publications from six randomized controlled trials $\mathrm{s}^{29-33,35}$ and five observational studies. ${ }^{36-40}$ The biochemical markers were alkaline phosphatase or bone-specific alkaline phosphatase (BAP; ten publications), type 1 collagen N-telopeptide (NTx; ten publications), type 1 collagen C-telopeptide (CTx; three publications), osteocalcin (one publication), tartrate-resistant acid phosphatase (one publication), and deoxypyridinoline (one publication) (Table 3). Findings were reported as the percentage change in concentration from baseline to 52 weeks or concentration at baseline and at 52 weeks.

Concentrations of all biochemical markers of bone turnover assessed decreased after 52 weeks of treatment with raloxifene (Table 3). The decreases in the biochemical marker concentrations from baseline were statistically significant when statistical significance was reported. When reported, the mean percentage decrease in concentrations after 52 weeks of treatment with raloxifene varied from $10 \%{ }^{31}$ to $38 \%{ }^{30}$ for BAP and $13.5 \%{ }^{39}$ to $35 \%{ }^{29,31}$ for NTx. In the randomized comparative trial of raloxifene and alendronate, ${ }^{31}$ the mean percentage decreases in serum alkaline phosphatase concentrations after 52 weeks of treatment and urinary NTx concentrations after 12 weeks of treatment were less for raloxifene than alendronate (alkaline phosphatase not significant, NTx $P<0.05$, Table 3 ). In the randomized comparative trials of raloxifene and alfacalcidol, the effect of raloxifene on BAP, NTx, and CTx concentrations was more pronounced than that of alfacalcidol after 52 and 104 weeks of treatment, ${ }^{32}$ and was less pronounced, similar to, or more pronounced than that combination treatment with raloxifene and alfacalcidol (Table 3). ${ }^{29,32,33}$ 
Table 3 Studies reporting mean (SD) percentage change in or mean (SD) concentrations for biochemical markers of bone turnover after 52 weeks of RLX treatment

\begin{tabular}{|c|c|c|c|c|}
\hline Authors & Therapy & $\begin{array}{l}\text { Serum BAP } \\
\text { (\% or U/L) }\end{array}$ & $\begin{array}{l}\text { CTx } \\
\text { (\% or } \mu g / L)\end{array}$ & $\begin{array}{l}\text { NTx } \\
\text { (\% or nmol BCE/L) }\end{array}$ \\
\hline \multicolumn{5}{|c|}{ Randomized controlled trials } \\
\hline \multirow[t]{2}{*}{ Morii et $\mathrm{a}^{35, \mathrm{a}, \mathrm{b}}$} & RLX & $N R(N R)^{* * *}$ & $\mathrm{NR}(\mathrm{NR})^{* * *, c}$ & $N R(N R)^{* * *, c}$ \\
\hline & $\mathrm{RLX}(\mathrm{I} 20 \mathrm{mg} /$ day $)$ & NR $(N R)^{* * *}$ & NR $(N R)^{* * *, c}$ & $N R(N R)^{* * *, c}$ \\
\hline \multirow[t]{2}{*}{ Iwamoto et $\mathrm{al}^{3 \mid}$} & ALN & $-18(N R)^{* * *, d}$ & NM & $-45(\mathrm{NR})^{* * *, c, \mathrm{e}}$ \\
\hline & RLX & $-10(\mathrm{NR})^{* * *, d}$ & NM & $-35(\mathrm{NR})^{* * *, c, \mathrm{e}}$ \\
\hline \multirow[t]{2}{*}{ Majima et $\mathrm{al}^{33}$} & RLX & $-20(37)^{*}$ & NM & $-29(20)^{* *, f}$ \\
\hline & $R L X+A L F$ & $-20(29)^{* *}$ & NM & $-25(17)^{* *, f}$ \\
\hline \multirow[t]{3}{*}{ Gorai et $\mathrm{al}^{29, \mathrm{~g}}$} & RLX & $-22(N R)$ & $-37(N R)^{c}$ & $N R(N R)^{c}$ \\
\hline & ALF & $N R(N R)$ & $N R(N R)^{c}$ & $N R(N R)^{c}$ \\
\hline & $R L X+A L F$ & -37 (NR) & $-42(N R)^{c}$ & $-35(N R)^{c}$ \\
\hline \multirow[t]{3}{*}{ Gorai et al $\mathrm{a}^{32, \mathrm{a}}$} & RLX & $N R(N R)^{*}$ & $\mathrm{NR}(\mathrm{NR})^{* * *, c}$ & $N R(N R)^{* * *, c}$ \\
\hline & ALF & $N R(N R)$ & $N R(N R)$ & $N R(N R)$ \\
\hline & $R L X+A L F$ & $N R(N R)^{* * *}$ & NR $(\mathrm{NR}) * * *, c$ & $N R(N R)^{* * *, c}$ \\
\hline \multirow[t]{3}{*}{ Ando et $\mathrm{al}^{30, \mathrm{~g}, \mathrm{~h}}$} & All & $-32(-43 \text { to }-22)^{i}$ & NM & NM \\
\hline & RLX am & $-26(-39 \text { to }-13)^{i}$ & NM & NM \\
\hline & $\mathrm{RLX} p \mathrm{~m}$ & $-38(-55 \text { to }-21)^{i}$ & NM & NM \\
\hline \multicolumn{5}{|c|}{ Observational studies } \\
\hline Majima et al ${ }^{36}$ & RLX & $33(16), 24(9)^{* *}$ & NM & $19(6), 14(3)^{* *, f}$ \\
\hline Majima et $\mathrm{al}^{37}$ & RLX & $33(17), 23(9)^{* *}$ & NM & $19(5), 14(3)^{* *, f}$ \\
\hline Majima et al ${ }^{38}$ & RLX & $33(16), 24(9)^{* *}$ & NM & $20(5), 14(3)^{* *, f}$ \\
\hline likuni et $\mathrm{al}^{40, \mathrm{a}, \mathrm{j}}$ & RLX & NR (NR)*** & NM & NR (NR) $)^{* * *, c}$ \\
\hline Takada et $\mathrm{al}^{39,8}$ & RLX & NM & NM & $-13.5(N R)^{f, k}$ \\
\hline
\end{tabular}

Notes: $* P<0.05, * * P<0.01$, and $* * * P<0.001$ indicate significant differences from baseline; ${ }^{\text {astudy }}$ presented data of biochemical markers of bone turnover in figures, but did not report specific values in the figure or results text; bosteocalcin levels were also measured in this study; statistically significant $(P<0.00 \mathrm{I})$ reductions from weeks 0 to 52 were reported; ' curinary levels tested; 'serum alkaline phosphatase levels were measured; ' $m e a n(\mathrm{SD})$ percentage change for NTx is from week 0 to week I2; fserum levels tested; gauthors did not specify the value of statistical significance for bone biochemical marker reductions; 'tartrate-resistant acid phosphatase levels were also measured in this study; the mean $(95 \% \mathrm{Cl})$ percentage change from week 0 to 52 was -27 ( -33 to $-2 \mathrm{I}) \mathrm{mU} / \mathrm{dL}$ for all postmenopausal women, $-3 \mathrm{I}$ ( -40 to -22$) \mathrm{mU} / \mathrm{dL}$ for the $\mathrm{RLX}$ am group, and $-23(-32$ to -14$) \mathrm{mU} / \mathrm{dL}$ for the $\mathrm{RLX}$ pm group; 'values are means $(95 \% \mathrm{Cl})$; 'urinary deoxypyridinoline levels were also measured in this study; statistically significant $(P<0.00 \mathrm{I})$ reductions from week 0 to 52 were reported; "kalues are medians; median percentage change for NTx is from week 0 to week 26.

Abbreviations: ALF, alfacalcidol; ALN, alendronate; BAP, bone-specific alkaline phosphatase; BCE, bone collagen equivalents; CTx, type I collagen C-telopeptide; NM, not measured; NR, not reported; NTx, type I collagen N-telopeptide; RLX, raloxifene 60 mg/day; SD, standard deviation; Cl, confidence interval.

\section{Hip structural geometry}

Findings for the hip structural geometry in the proximal femur were reported in two of the 15 publications, both of which were prospective observational studies..$^{24,39}$ The hip-structure analysis parameters were the cross-sectional area, mean cortical thickness, section modulus and buckling ratio of the narrow neck, intertrochanter, and shaft regions of the proximal femur; one publication reported the inner diameter, ${ }^{39}$ and the other reported the outer diameter. ${ }^{24}$ Findings were reported as the mean $(95 \%$ confidence interval [CI]) percentage change in parameters from baseline to 52 weeks in both publications and from baseline to 104 weeks in one publication. ${ }^{24}$

Nearly all hip-structure analysis parameters for the intertrochanter and shaft regions of the proximal femur improved significantly after 52 weeks of treatment with raloxifene. For the intertrochanter and shaft regions, there were significant $(P<0.05)$ increases in the cross-sectional area, mean cortical thickness, and section modulus after 52 weeks ${ }^{24,39}$ and 104 weeks $^{24}$ of raloxifene treatment. In addition, there was a significant $(P<0.05)$ decrease in the buckling ratio of the intertrochanter and shaft regions in one publication ${ }^{39}$ and in the intertrochanter region in the other publication. ${ }^{24}$ However, this difference for the intertrochanter region was not significant at 104 weeks. ${ }^{24}$ In contrast, only a few hipstructure analysis parameters for the narrow neck regions for the proximal femur had improved significantly after 52 weeks of treatment with raloxifene. ${ }^{24}$ These significant improvements $(P<0.05)$ included increases in the cross-sectional area, section modulus, and outer diameter. ${ }^{24}$

\section{Blood-lipid parameters}

Findings for blood-lipid parameters were reported in five of the 15 publications, including publications from four randomized controlled trials $\mathrm{s}^{31,33-35}$ and one prospective observational study. ${ }^{36}$ The blood-lipid parameters were total cholesterol (four publications), high-density lipoprotein cholesterol (five publications), low-density lipoprotein (LDL) cholesterol 
Table 4 Studies reporting mean (SD) percentage change in blood-lipid parameters or mean (SD) blood-lipid parameters after 52 weeks of RLX treatment

\begin{tabular}{|c|c|c|c|c|c|}
\hline Authors & Therapy & $\begin{array}{l}\text { Total cholesterol } \\
\% \text { or } \mathrm{mg} / \mathrm{dL}\end{array}$ & $\begin{array}{l}\text { Triglycerides } \\
\% \text { or } \mathrm{mg} / \mathrm{dL}\end{array}$ & $\begin{array}{l}\text { HDL-cholesterol } \\
\% \text { or } \mathrm{mg} / \mathrm{dL}\end{array}$ & $\begin{array}{l}\text { LDL-cholesterol } \\
\% \text { or } \mathrm{mg} / \mathrm{dL}\end{array}$ \\
\hline \multicolumn{6}{|c|}{ Randomized controlled trials } \\
\hline \multirow[t]{2}{*}{ Morii et $\mathrm{a}^{35}$} & $\mathrm{RLX}$ & $\mathrm{NR}(\mathrm{NR})^{*, a}$ & NR (NR) & NR (NR) & $N R(N R)^{*, a}$ \\
\hline & $\operatorname{RLX}(120 \mathrm{mg} /$ day $)$ & $N R(N R)^{*, a}$ & $N R(N R)$ & $N R(N R)$ & $N R(N R)^{*, a}$ \\
\hline \multirow[t]{2}{*}{ Iwamoto et $\mathrm{a}^{3 \mid}$} & RLX & $-3.9(N R)^{* *}$ & +7.4 (NR) & +5.1 (NR) & $-7.7(\mathrm{NR}) * * *$ \\
\hline & ALN & $-2.1(\mathrm{NR})$ & $-3.4(\mathrm{NR})$ & $-0.4(\mathrm{NR})$ & $+0.4(\mathrm{NR})$ \\
\hline \multirow[t]{2}{*}{ Majima et $\mathrm{al}^{33}$} & RLX & $202(39), 184(30)^{* *}$ & I $33(74), 125(58)$ & 57 (I4), 53 (II) & $119(38), 106(24)$ \\
\hline & $\mathrm{RLX}+\mathrm{ALF}$ & $210(29), 199(28)^{*}$ & I 44 (58), I 24 (72) & $57(15), 56(15)$ & $125(30), 118(27)$ \\
\hline \multirow[t]{3}{*}{ Hayashi et $\mathrm{al}^{34}$} & RLX & NR (NR), NR (NR) & $95(24), 86(\mathrm{II})$ & $56(6), 64(7)^{*}$ & $113(14), 102(15)$ \\
\hline & HRT & NR (NR), NR (NR) & $96(25), 97$ (18) & $57(5), 56(8)$ & $112(11), 114(13)$ \\
\hline & Control & $N R(N R), N R(N R)$ & $97(2 \mathrm{I}), 95(2 \mathrm{I})$ & $57(5), 56(6)$ & $119(11), 125(9)$ \\
\hline \multicolumn{6}{|c|}{ Observational studies } \\
\hline Majima et $a^{36}$ & RLX & $204(32), 192(31)^{* *}$ & $123(66), 122(63)$ & 55 (I3), $54(\mathrm{II})$ & $125(33), 113(27)^{*}$ \\
\hline
\end{tabular}

Notes: $* P<0.05, * * P<0.01$, and $* * * P<0.001$ indicate significant differences from baseline; ${ }^{2}$ statistical significance is for differences between placebo and RLX groups at week 52.

Abbreviations: ALF, alfacalcidol; ALN, alendronate; HDL, high-density lipoprotein; HRT, hormone-replacement therapy; LDL, low-density lipoprotein; NR, not reported; RLX, raloxifene $60 \mathrm{mg} /$ day; SD, standard deviation.

(five publications), and triglycerides (five publications) (Table 4). Findings were reported as the percentage change in concentration from baseline to 52 weeks or concentration at baseline and at 52 weeks.

In general, the blood-lipid profile of participants had improved after 52 weeks of treatment with raloxifene (Table 4). Decreases in the concentrations of both total cholesterol and LDL cholesterol from baseline concentrations were reported in all publications reporting findings of these parameters. These decreases were statistically significant for total cholesterol concentrations in three publications ${ }^{31,33,36}$ and LDL cholesterol concentrations in two publications. ${ }^{31,36}$ The concentration of high-density lipoprotein cholesterol was significantly increased $(P<0.05)$ in one publication, ${ }^{34}$ but remained the same in the four other publications (Table 4). The concentration of triglycerides either decreased or remained the same (Table 4).

In the randomized controlled trial, decreases in total cholesterol concentrations and LDL cholesterol concentrations were significantly greater $(P<0.05)$ for participants receiving raloxifene $(60 \mathrm{mg} /$ day and $120 \mathrm{mg} /$ day $)$ than those receiving placebo after 52 weeks of treatment. ${ }^{35}$ In the randomized comparative trial of raloxifene and alendronate, decreases in LDL cholesterol concentrations were significantly greater $(P<0.05)$ for participants receiving raloxifene than those receiving alendronate after 52 weeks of treatment. ${ }^{31}$

\section{Safety}

Findings for safety variables were reported in 12 of the 15 publications: publications from six randomized controlled trials ${ }^{29-33,35}$ and six observational studies. ${ }^{36-38,40-42}$ Safety variables were the type, incidence, and severity of AEs (four publications) (Table 5), study discontinuations resulting from AEs (nine publications) (Table 6), stroke risk (one publication), ${ }^{41}$ and change in markers of coagulation and fibrinolysis (one publication). ${ }^{30}$ Three publications from one randomized controlled trial ${ }^{34}$ and two observational studies ${ }^{24,39}$ did not report findings for any safety variables.

The type, incidence, and severity of AEs were reported in four publications from two randomized controlled trials $\mathrm{s}^{29,35}$ and two observational studies, ${ }^{40,42}$ both of which were postmarketing surveillance studies (Table 5). The safety findings were consistent with those expected for raloxifene use in Japan. ${ }^{44}$ In the randomized placebo-controlled trial, ${ }^{35}$ almost half of the participants reported at least one $\mathrm{AE}$, whereas about $10 \%$ of the participants in the long-term postmarketing surveillance study reported an AE. ${ }^{40}$ Few postmenopausal women had hot flushes, leg cramps, breast pain, or vaginal bleeding (when reported) in the randomized trials (Table 5). Clinically relevant abnormal changes in breast tissue were reported in one woman taking raloxifene $120 \mathrm{mg} /$ day (inspection and palpation) and in one woman taking placebo (ultrasound examination) in the randomized placebo-controlled trial. ${ }^{35}$ In addition, clinically relevant abnormal changes in endometrial thickness were reported in two women taking raloxifene $60 \mathrm{mg} /$ day and one woman taking raloxifene $120 \mathrm{mg} /$ day. ${ }^{35}$ Common AEs reported in the postmarketing surveillance studies were peripheral edema and abdominal discomfort (Table 5). 
Table 5 Adverse events (AEs)

\begin{tabular}{|c|c|c|c|c|c|}
\hline Authors & Therapy (n) & $\begin{array}{l}\text { AEs } \\
n\end{array}$ & $\begin{array}{l}\text { Serious AEs } \\
\mathbf{n}\end{array}$ & $\begin{array}{l}\text { Death } \\
\text { n }\end{array}$ & Other \\
\hline \multicolumn{6}{|c|}{ Randomized controlled trials } \\
\hline \multirow[t]{3}{*}{ Morii et $\mathrm{al}^{35}$} & $\operatorname{RLX}(92)$ & 32 & 5 & 0 & No significant increases in incidence of hot flushes, leg cramps, \\
\hline & $\operatorname{RLX}(120$ mg/day) (95) & 40 & 3 & $\mathrm{I}^{\mathrm{b}}$ & breast pain or vaginal bleeding between RLX and placebo \\
\hline & Placebo (97) & 33 & $7^{\mathrm{a}}$ & 0 & groups; no VTE events reported \\
\hline \multirow[t]{3}{*}{ Gorai et al29,c } & $\operatorname{RLX}(45)$ & 17 & NR & NR & Hot flush I, leg cramp 2, limb cramp 2 \\
\hline & ALF (44) & 11 & NR & NR & Hot flush I \\
\hline & $\mathrm{RLX}+\mathrm{ALF}(48)$ & 13 & NR & NR & Leg cramp 2 \\
\hline \multicolumn{6}{|c|}{ Observational studies } \\
\hline \multirow[t]{2}{*}{ likuni et $\mathrm{al}^{40}$} & $\operatorname{RLX}(6,967)$ & $776^{d}$ & $76^{d}$ & 3 & Stroke I2 (8 serious), VTE II (3 serious) \\
\hline & & & & & $\begin{array}{l}\text { Most frequent AEs: peripheral edema } 45 \text {, abdominal } \\
\text { discomfort } 39 \text {, abdominal pain } 33\end{array}$ \\
\hline Yoh et $\mathrm{al}^{42}$ & $\operatorname{RLX}(506)$ & $34^{\mathrm{e}}$ & I & 0 & Most frequent AEs: abdominal discomfort 6, peripheral edema \\
\hline
\end{tabular}

Notes: aSeven participants reported nine serious AEs; 'beath caused by anaplastic thyroid cancer; not related to RLX; 'adverse events were self-reported or observed; d96I AEs were reported in 775 participants, and 87 serious AEs were reported in 76 participants; ${ }^{e} 40$ AEs were reported in 34 participants.

Abbreviations: ALF, alfacalcidol; NR, not reported; RLX, raloxifene $60 \mathrm{mg} /$ day; VTE, venous thromboembolism.

In a postmarketing surveillance study of 6,970 postmenopausal women, the risk of stroke was not significantly increased after 52 weeks of treatment with raloxifene. ${ }^{41}$ In this study, 23 treatment-emergent stroke cases were reported (crude stroke risk $=0.33 \%$ ). Of these 23 cases, four had a previous history of stroke, nine had risk factors for stroke (eg, hypertension), and ten had no risk factors for stroke. Four women died as a result of stroke. ${ }^{41}$ In another postmarketing surveillance study of 6,967 postmenopausal women, there were 12 cases of stroke, eight of which were serious, after 156 weeks of treatment with raloxifene. ${ }^{40}$

Although no VTE events were reported in the randomized placebo-controlled trial, there were eleven cases of VTE, three of which were serious, in the 3-year postmarketing surveillance study (Table 5). In another publication, the concentration of plasminogen-activator inhibitor, a marker for the increased risk of VTE, was increased after 52 weeks of treatment with raloxifene. ${ }^{30}$ This increase in

Table 6 Study discontinuations

\begin{tabular}{|c|c|c|c|c|}
\hline Authors & Therapy (n) & $\begin{array}{l}\text { Overall } \\
\text { n }\end{array}$ & $\begin{array}{l}\text { Because of AEs } \\
n\end{array}$ & $\begin{array}{l}\text { AE type } \\
\text { n }\end{array}$ \\
\hline \multicolumn{5}{|c|}{ Randomized controlled trials } \\
\hline \multirow[t]{3}{*}{ Morii et $\mathrm{al}^{35}$} & $\operatorname{RLX}(92)$ & 13 & 7 & NR \\
\hline & RLX (I 20 mg/day) (95) & 14 & 8 & NR \\
\hline & Placebo (97) & 10 & 3 & NR \\
\hline \multirow[t]{2}{*}{ Iwamoto et $\mathrm{al}^{3 \mid}$} & $\operatorname{RLX}(6 I)$ & 9 & 6 & Epigastric pain 4, liver dysfunction I, urticaria I \\
\hline & ALN (6I) & 11 & 8 & $\begin{array}{l}\text { Epigastric pain 3, gastric ulcer I, heartburn I, liver dysfunction I, } \\
\text { diarrhea I, constipation I }\end{array}$ \\
\hline \multirow[t]{2}{*}{ Majima et $\mathrm{al}^{33}$} & $\operatorname{RLX}(32)$ & 10 & 2 & Muscle pain entire body I, leg cramps I $^{\mathrm{a}}$ \\
\hline & $R L X+A L F(28)$ & 8 & 2 & Increased BP I, leg cramps I ${ }^{a}$ \\
\hline \multirow[t]{3}{*}{ Gorai et $\mathrm{al}^{29}$} & $\operatorname{RLX}(45)$ & NR & 7 & Itching paresthesia 2, limb cramp 2, leg cramp 2, alopecia areata I \\
\hline & $\operatorname{ALF}(44)$ & NR & 5 & Hypercalciuria 4 , hot flash I \\
\hline & $R L X+A L F(48)$ & NR & 6 & Digestive symptoms 3 , leg cramp 2 , angina attack I \\
\hline \multirow[t]{3}{*}{ Gorai et $\mathrm{al}^{32}$} & $\operatorname{RLX}(42)$ & NR & 7 & Itching paresthesia 2, limb cramp 2, leg cramp 2, alopecia areata I \\
\hline & $\operatorname{ALF}(46)$ & NR & 5 & Hypercalciuria 4 , hot flash I \\
\hline & $\mathrm{RLX}+\mathrm{ALF}(45)$ & NR & 6 & Digestive symptoms 3 , leg cramp 2 , angina attack I \\
\hline \multirow[t]{2}{*}{ Ando et $\mathrm{al}^{30}$} & RLX am (20) & 4 & 3 & Muscle pain I, headache I, loss of fingernails I \\
\hline & $\operatorname{RLX} p m(19)$ & I & $\mathrm{I}$ & Hot flush I \\
\hline \multicolumn{5}{|c|}{ Observational studies } \\
\hline Majima et $\mathrm{al}^{36}$ & $\operatorname{RLX}(50)$ & 16 & 4 & Leg cramps 2, muscle pain entire body I, increased BP Ia \\
\hline Majima et $\mathrm{al}^{37}$ & $\operatorname{RLX}(68)$ & 10 & 2 & Leg cramps I, muscle pain entire body $\mathrm{I}^{\mathrm{a}}$ \\
\hline Majima et $\mathrm{al}^{38}$ & $\operatorname{RLX}(73)$ & 10 & 2 & Leg cramps I, muscle pain entire body $\mathrm{I}^{\mathrm{a}}$ \\
\hline
\end{tabular}

Note: aAEs resolved spontaneously with cessation of RLX.

Abbreviations: AEs, adverse events; ALF, alfacalcidol; ALN, alendronate; BP, blood pressure; NR, not reported; RLX, raloxifene 60 mg/day. 
plasminogen activator-inhibitor concentration was noted for participants taking raloxifene in the morning, but not those taking raloxifene in the evening, suggesting that dosing time may have influenced the safety of raloxifene in this study population.

Study discontinuations resulting from AEs were reported in nine publications from six randomized controlled trials $^{29-33,35}$ and three observational studies (Table 6). ${ }^{36-38}$ Few participants discontinued treatment because of AEs; leg and limb cramps, and muscle pain were the most common reasons for participants discontinuing raloxifene treatment (Table 6).

\section{Quality of life and pain}

Findings for quality of life and pain were reported in one publication from a postmarketing surveillance study. ${ }^{42}$ In this publication, quality of life was assessed using the Short Form (SF)-8 Health Survey, the European Quality of Life Instrument, and the Japanese Osteoporosis Quality of Life Questionnaire, whereas pain was assessed using a visual analog scale and a pain-frequency survey. Findings were reported as the mean (standard deviation) change in scores from baseline to 24 weeks.

Improvement in quality of life and relief from pain was reported after 24 weeks of treatment with raloxifene. ${ }^{42}$ All scores for the SF-8 domains (general health, physical functioning, role physical, bodily pain, vitality, social functioning, mental health, and role - emotional) improved significantly $(P<0.001)$ from baseline, as did the European Quality of Life Instrument score. Significant improvements $(P<0.05)$ in the total score and the scores of individual domains, except for the recreation/social activities domain, for the Japanese Osteoporosis Quality of Life Questionnaire were also reported. Relief from pain was indicated by a significant decrease $(P<0.001)$ in pain severity (decreased visual analog scale scores) and decreases in the frequency of pain (fewer participants reporting permanent frequent pain).

\section{Discussion}

This is the first systematic review describing the efficacy, effectiveness, and safety outcomes of postmenopausal Japanese women with osteoporosis or osteopenia treated with raloxifene. Overall, a broad range of outcomes were reported for raloxifene (eg, BMD, bone turnover, lipid metabolism, AEs) in randomized controlled studies and observational studies, which included postmarketing surveillance studies. Despite the variation in study designs and methods reported, the body of evidence in this systematic review supports the effectiveness of raloxifene in increasing lumbar spine BMD and reducing the incidence of subsequent fracture, is associated with improvements in other healthoutcome measures, and is well tolerated in postmenopausal Japanese women. When reported, lumbar spine BMD increased significantly, ${ }^{29,31-33,35-38,40}$ and biochemical markers of bone turnover decreased after 52 weeks of treatment with raloxifene. ${ }^{29-33,35-40}$ However, limited data were available to confirm whether these improvements in bone quality were associated with a reduction in the incidence of vertebral or nonvertebral fracture in postmenopausal Japanese women. The AEs reported in the studies included in this review were consistent with the safety profile of raloxifene use in Japan. ${ }^{44}$

In bone cells, where postmenopausal estrogen deficiency has caused an imbalance in bone turnover (excess resorption versus formation), raloxifene binds to estrogen receptors and induces conformational changes that are distinct from the binding of estrogen. ${ }^{45}$ Raloxifene then acts as an agonist to decrease bone resorption and normalize bone turnover, thereby preserving BMD. In the MORE (Multiple Outcomes of Raloxifene Evaluation) study (a pivotal multicenter, international, blinded, randomized, placebo-controlled trial of 7,705 postmenopausal women with osteoporosis from Europe, the Americas, and Oceania), ${ }^{46}$ raloxifene was shown to increase BMD, improve bone strength, and prevent vertebral fractures, but not to reduce the risk of nonvertebral fractures as a primary outcome. ${ }^{47,48}$ In our systematic review, the increase in lumbar spine BMD and decrease in biochemical markers of bone turnover in postmenopausal Japanese women support the findings from the pivotal studies of raloxifene conducted in Caucasian populations. ${ }^{47,48}$ In another publication excluded from our review (because it was published in a non-peer-reviewed journal), the increase in lumbar spine BMD reported for raloxifene was $7.1 \%$ at 26 weeks. ${ }^{49}$ In this study, raloxifene was coadministered with eldecalcitol, an active vitamin $\mathrm{D}_{3}$ analog, which has been shown to enhance the mechanical properties of trabecular and cortical bone by suppressing bone turnover and increasing BMD more than either monotherapy in ovariectomized rats. ${ }^{50}$ Although in our review there were few head-to-head studies of raloxifene compared with other osteoporosis medications, the data available suggest that the effect of raloxifene on BMD and biochemical markers of bone turnover was not as pronounced as that of alendronate. ${ }^{31}$ However, it is not clear how these findings translate to any potential 
differences in the effect of raloxifene on new vertebral fractures, because of the limited length of follow-up (52 weeks) and because this study was not sufficiently powered to assess incidence of vertebral fracture. ${ }^{31}$

We identified only one publication sufficiently powered to detect vertebral fracture incidence. In this postmarketing surveillance study ${ }^{40}$ of Japanese women with osteoporosis treated with raloxifene, the low incidence of vertebral fractures was consistent with findings from the MORE study ${ }^{47,48}$ and a post hoc analysis of combined study data from postmenopausal Japanese ${ }^{35}$ and Chinese women with osteoporosis. ${ }^{28}$ Interestingly, the incidence of new clinical nonvertebral fractures $(0.7 \%)$ was slightly higher than new clinical vertebral fractures $(0.5 \%)$ in the postmarketing surveillance study. ${ }^{40}$ This finding may have been due to the criteria used to define new clinical fractures (reported signs or symptoms suggestive of fracture subsequently corroborated by radiographs) that excluded vertebral morphometry, which may have identified more patients with a vertebral fracture. In the post hoc analysis, which was not included in this systematic review because the analysis combined data from both Japanese and Chinese populations, the incidence of new clinical vertebral fractures was significantly lower for postmenopausal Japanese and Chinese women taking raloxifene $(60 \mathrm{mg} /$ day or $120 \mathrm{mg} /$ day $)$ than those taking placebo (0 of 289 versus seven of 199 $[3.5 \%], P=0.002) .^{28}$

Treatments that help improve lumbar spine BMD and bone quality and consequently reduce the incidence of vertebral fracture (which includes preventing or reducing the risk of subsequent vertebral and/or nonvertebral fractures) are important in Japanese populations. This is because the incidence of vertebral fractures in Japanese women appears to be higher than in Caucasian women. In studies using similar morphometric methods, the incidence of vertebral fracture in the Japanese study was about 40 per 1,000 person-years for women in their $70 \mathrm{~s},{ }^{15}$ whereas the incidence in studies of Caucasian women of a similar age are about twofold lower. ${ }^{16,17,51}$ In another study, the prevalence of vertebral fracture in 70- to- 74-year-old women was greater in Japanese women (248 cases per 1,000) than women of Japanese descent (148 cases per 1,000) or Caucasian women (150 cases per 1,000). ${ }^{52}$ The higher incidence of vertebral fractures for Japanese women is also apparent compared with women from other Asian countries. The prevalence of vertebral fractures was significantly greater in women aged 65-74 years from Japan than those from Hong Kong,
Indonesia, and Thailand. ${ }^{53}$ Factors specific to the Japanese lifestyle, culture, and ethnicity may influence the risk of fracture in Japanese women. ${ }^{54}$ For example, BMD is lower in Japanese women than Caucasian women of the same age. ${ }^{43,55}$ Other factors shown to be possibly associated with vertebral fractures in Japan include weight, age, menstrual history, ${ }^{56}$ genetic factors,${ }^{57}$ bone and calcium metabolism, ${ }^{58}$ calcium intake, ${ }^{59}$ and vitamin D levels. ${ }^{60}$ All of these factors contribute to BMD levels, and thus may indirectly influence the prevalence of vertebral fractures. However, although these other factors may contribute indirectly, future fracture risk in women from Japan can be accurately predicted using age, BMD, and prior vertebral fracture status. ${ }^{61}$

Findings from this review showed that although proximal femur structural geometry improved with raloxifene treatment, ${ }^{24,39}$ the effect of raloxifene on the BMD of the femoral neck, total hip, total neck, or other regions of the hip in postmenopausal Japanese women was variable. . $2,29,32,33,36-39$ This variable effect on BMD in the hip region may be explained, at least in part, by participants having different BMD values for the hip region at baseline, because specific BMD values for the hip region were not an inclusion criterion in studies reporting these findings. ${ }^{24,29,32,33,36-39}$ Hip-structure analysis is a valuable measure of proximal femur geometry and strength ${ }^{62}$ that has been used to show age-, ethnic-, and sex-related differences in proximal femur geometry and strength, ${ }^{63-67}$ as well as the effects of osteoporotic treatments..$^{25,68-71}$ The findings from the studies that assessed hip structure ${ }^{24,39}$ suggest that raloxifene may have a beneficial effect on hip-bone quality. However, although this effect may translate to a reduction in the likelihood of hip fracture, there is no published evidence available to show that treatment with raloxifene reduces the incidence of hip fracture in postmenopausal women with osteoporosis.

The safety and tolerability findings in the publications included in this review suggested that raloxifene was well tolerated in most postmenopausal women in Japan. Few postmenopausal women discontinued because of AEs, and few postmenopausal women experienced AEs commonly associated with raloxifene use, such as leg cramps, hot flushes, and peripheral edema. ${ }^{22}$ The main safety concern of treatment with raloxifene is an increased risk of VTE. ${ }^{22}$ Although the incidence of VTE in clinical studies of raloxifene is low, findings from the pivotal MORE study, which excluded women with a history of thromboembolic events in the past 10 years, showed that the relative risk of VTE was 
$3.1(95 \% \text { CI 1.5-6.2 })^{46}$ and of pulmonary embolism was 4.5 (95\% CI 1.1-19.5) $)^{72}$ for raloxifene compared with placebo at 36 months. The estimated incidence of deep vein thrombosis in Japanese people is a tenth of that in Caucasian people (42 versus $370-420$, respectively, per 1,000,000 people), ${ }^{73}$ and the findings of this systematic review confirmed the low incidence of VTE in postmenopausal Japanese women taking raloxifene..$^{35,40}$ In addition, evidence from largescale postmarketing surveillance studies showed that the incidence of stroke or fatal stroke was not different from the general female Japanese population after 1 year $^{41}$ or 3 years ${ }^{75}$ of treatment with raloxifene. Although the bloodlipid profile of postmenopausal women taking raloxifene had improved (eg, decreases in both total cholesterol and LDL cholesterol), ${ }^{21,33,35,36}$ there is no evidence that improved blood-lipid profiles are associated with better cardiovascular outcomes in postmenopausal women at increased risk of coronary heart disease. ${ }^{75}$

This systematic review retrieved only one publication reporting quality-of-life and pain findings in Japanese women. In this postmarketing surveillance study, ${ }^{42}$ treatment with raloxifene improved health-related quality-of-life scores and relieved pain. This study is important, because prevalent vertebral fractures can be a major contributor to the health-related quality of life of postmenopausal women with osteoporosis. In particular, multiple vertebral fractures are of concern in Japan, as they are associated with chronic pain and incapacitating spinal deformities, deterioration in activities of daily living, and an increased risk of death. ${ }^{9-14}$ Specifically, morphometric vertebral fracture in Japanese women is significantly associated with lower health-related quality-of-life scores, ${ }^{76}$ and this loss of health-related quality of life occurred after incident vertebral fracture. ${ }^{77}$ Further, in Japan, osteoporosis may also be a significant burden on the patient's family, who are responsible for providing caregiving support to elderly family members with osteoporosis.

There were several limitations with this systematic review. First, although the publications included in this review reported a broad range of findings for raloxifene (eg, BMD, bone turnover, lipid metabolism, and AEs), these findings were limited by the different methods used and the study quality (ie, there was only one placebo-controlled randomized trial and one randomized trial comparing raloxifene with a bisphosphonate). Second, few publications assessed raloxifene treatment for more than 1 year, despite the increased risks of VTE and stroke with long-term use of raloxifene. ${ }^{75}$ Third, publications of raloxifene coadministered with active metabolites of vitamin D were included. However, excluding these studies is not clinically appropriate, because active vitamin $\mathrm{D}_{3}$ analogs are widely prescribed in Japan concomitantly with antiresorptive agents to compensate for calcium absorption and inhibit subsequent parathyroid hormone secretion in osteoporosis patients. Fourth, we did not provide a separate analysis of those studies in which raloxifene was coadministered with active metabolites of vitamin $\mathrm{D}$. Although active vitamin $\mathrm{D}_{3}$ analogs are widely prescribed in Japan concomitantly with antiresorptive agents, only three ${ }^{29,32,33}$ of the 15 publications included in this review assessed patients taking concomitant raloxifene and active vitamin $\mathrm{D}_{3}$ analogs (alfacalcidol), and all included raloxifene monotherapy treatment groups. Last, although there were no restrictions on language and the bibliographies of retrieved systematic reviews were hand-searched to identify any publications not retrieved in the electronic search, other nonindexed publications and unpublished data were not included.

In conclusion, osteoporosis is a major health problem in the aging population of Japan and is underdiagnosed and undertreated. ${ }^{78}$ If left untreated, fracture may occur, resulting in considerable pain and decreased health-related quality of life. Findings from this systematic review support the efficacy and effectiveness of raloxifene for preventing or reducing the risk of subsequent vertebral and/or nonvertebral fractures by improving BMD and reducing bone turnover in postmenopausal Japanese women with osteoporosis or osteopenia. Other findings suggest that raloxifene is well tolerated and can improve quality of life. However, these findings should be considered in light of the limitations of the publications and the risk-benefit profile of raloxifene.

\section{Acknowledgments}

The authors thank Shuko Nojiri of Eli Lilly Japan K.K. for her contributions on earlier versions of this review. Medical writing assistance was provided by Julie Monk, PhD and Serina Stretton, PhD, CMPP (Certified Medical Publication Professional) of ProScribe Medical Communications, and was funded by Eli Lilly Japan K.K. ProScribe's services complied with international guidelines for Good Publication Practice (GPP2).

\section{Disclosure}

The study was funded by Eli Lilly Japan K.K., the manufacturer of raloxifene and teriparatide. SF has received speaker honoraria and consulting fees from Eli Lilly Japan K.K., Asahi-Kasei, Astellas, Chugai, Daiichi-Sankyo, Eisai, Ono, 
MDS, and Pfizer. MS is an employee of Eli Lilly Japan K.K.; PGC is an employee of Eli Lilly Australia; JAF and RB are employees of Eli Lilly and Company; all are stock stockholders in Eli Lilly and Company. EH was an employee of Eli Lilly Japan K.K. when this manuscript was developed. EH is currently an employee of Amgen Astellas Biopharma K.K.

\section{References}

1. [No authors listed]. Who are candidates for prevention and treatment for osteoporosis? Osteoporos Int. 1997;7(1):1-6.

2. Yoshimura N, Muraki S, Oka H, et al. Prevalence of knee osteoarthritis, lumbar spondylosis, and osteoporosis in Japanese men and women: the research on osteoarthritis/osteoporosis against disability study. J Bone Miner Metab. 2009;27(5):620-628.

3. United Nations. World Mortality Report 2011. New York: UN; 2012. Available from: http://www.un.org/esa/population/publications/world mortalityreport2011/World\%20Mortality\%20Report\%202011.pdf. Accessed June 13, 2013.

4. Statistics Japan. Current population estimates as of October 1, 2012. Available from: http://www.stat.go.jp/english/data/jinsui/2012np/ index.htm. Accessed June 13, 2013.

5. Marshall D, Johnell O, Wedel H. Meta-analysis of how well measures of bone mineral density predict occurrence of osteoporotic fractures. BMJ. 1996;312(7041):1254-1259.

6. Briggs AM, Greig AM, Wark JD. The vertebral fracture cascade in osteoporosis: a review of aetiopathogenesis. Osteoporos Int. 2007; 18(5):575-584.

7. Klotzbuecher CM, Ross PD, Landsman PB, Abbott TA 3rd, Berger M. Patients with prior fractures have an increased risk of future fractures: a summary of the literature and statistical synthesis. J Bone Miner Res. 2000;15(4):721-739.

8. Lindsay R, Burge RT, Strauss DM. One year outcomes and costs following a vertebral fracture. Osteoporos Int. 2005;16(1):78-85.

9. Ikeda Y, Sudo A, Yamada T, Uchida A. Mortality after vertebral fractures in a Japanese population. J Orthop Surg (Hong Kong). 2010;18(2): $148-152$

10. Jinbayashi H, Aoyagi K, Ross PD, Ito M, Shindo H, Takemoto $\mathrm{T}$. Prevalence of vertebral deformity and its associations with physical impairment among Japanese women: the Hizen-Oshima Study. Osteoporos Int. 2002;13(9):723-730.

11. Miyakoshi N, Hongo M, Maekawa S, Ishikawa Y, Shimada Y, Itoi E. Back extensor strength and lumbar spinal mobility are predictors of quality of life in patients with postmenopausal osteoporosis. Osteoporos Int. 2007;18(10):1397-1403.

12. Miyakoshi N, Itoi E, Kobayashi M, Kodama H. Impact of postural deformities and spinal mobility on quality of life in postmenopausal osteoporosis. Osteoporos Int. 2003;14(12):1007-1012.

13. Suzuki N, Ogikubo O, Hansson T. Previous vertebral compression fractures add to the deterioration of the disability and quality of life after an acute compression fracture. Eur Spine J. 2010;19(4):567-574.

14. Takahashi T, Ishida K, Hirose D, et al. Trunk deformity is associated with a reduction in outdoor activities of daily living and life satisfaction in community-dwelling older people. Osteoporos Int. 2005; 16(3):273-279

15. Fujiwara S, Kasagi F, Masunari N, Naito K, Suzuki G, Fukunaga M. Fracture prediction from bone mineral density in Japanese men and women. J Bone Miner Res. 2003;18(8):1547-1553.

16. European Prospective Osteoporosis Study Group, Felsenberg D, Silman AJ, et al. Incidence of vertebral fracture in Europe: results from the European Prospective Osteoporosis Study (EPOS). J Bone Miner Res. 2002;17(4):716-724.

17. Van der Klift M, De Laet CE, McCloskey EV, Hofman A, Pols HA. The incidence of vertebral fractures in men and women: the Rotterdam Study. J Bone Miner Res. 2002;17(6):1051-1056.
18. Mithal A, Ebeling P. The Asia-Pacific Regional Audit. Epidemiology, Costs and Burden of Osteoporosis in 2013. Nyon, Switzerland: International Osteoporosis Foundation; 2013. Available from: http:// www.iofbonehealth.org/sites/default/files/media/PDFs/Regional $\% 20$ Audits/2013-Asia_Pacific_Audit_0_0.pdf. Accessed August 5, 2014.

19. Committee of Japanese Guidelines for the Prevention and Treatment of Osteoporosis. Japanese Guidelines for the Prevention and Treatment of Osteoporosis. Tokyo: Life Science; 2011.

20. Harada A, Matsui Y, Mizuno M, Tokuda H, Niino N, Ohta T. Japanese orthopedists' interests in prevention of fractures in the elderly from falls. Osteoporos Int. 2004;15(7):560-566.

21. Iwamoto J, Sato Y, Takeda T, Matsumoto H. Efficacy of antiresorptive agents for preventing fractures in Japanese patients with an increased fracture risk: review of the literature. Drugs Aging. 2012;29(3): 191-203.

22. Cranney A, Adachi JD. Benefit-risk assessment of raloxifene in postmenopausal osteoporosis. Drug Saf. 2005;28(8):721-730.

23. Kanis JA, Johnell O, Black DM, et al. Effect of raloxifene on the risk of new vertebral fracture in postmenopausal women with osteopenia or osteoporosis: a reanalysis of the Multiple Outcomes of Raloxifene Evaluation trial. Bone. 2003;33(3):293-300.

24. Takada J, Miki T, Imanishi Y, et al. Effects of raloxifene treatment on the structural geometry of the proximal femur in Japanese women with osteoporosis. J Bone Miner Metab. 2010;28(5):561-567.

25. Uusi-Rasi K, Beck TJ, Semanick LM, et al. Structural effects of raloxifene on the proximal femur: results from the Multiple Outcomes of Raloxifene Evaluation Trial. Osteoporos Int. 2006;17(4): 575-586.

26. Saito M, Marumo K, Soshi S, Kida Y, Ushiku C, Shinohara A. Raloxifene ameliorates detrimental enzymatic and nonenzymatic collagen cross-links and bone strength in rabbits with hyperhomocysteinemia. Osteoporos Int. 2010;21(4):655-666.

27. Boivin G, Lips P, Ott SM, et al. Contribution of raloxifene and calcium and vitamin D3 supplementation to the increase of the degree of mineralization of bone in postmenopausal women. J Clin Endocrinol Metab. 2003;88(9):4199-4205.

28. Nakamura T, Liu JL, Morii H, et al. Effect of raloxifene on clinical fractures in Asian women with postmenopausal osteoporosis. J Bone Miner Metab. 2006;24(5):414-418.

29. Gorai I, Tanaka Y, Hattori S, Iwaoki Y. Assessment of adherence to treatment of postmenopausal osteoporosis with raloxifene and/or alfacalcidol in postmenopausal Japanese women. J Bone Miner Metab. 2010;28(2):176-184.

30. Ando H, Otoda T, Ookami H, et al. Dosing time-dependent effect of raloxifene on plasma plasminogen activator inhibitor-1 concentrations in post-menopausal women with osteoporosis. Clin Exp Pharmacol Physiol. 2013;40(3):227-232.

31. Iwamoto J, Sato Y, Uzawa M, Takeda T, Matsumoto H. Comparison of effects of alendronate and raloxifene on lumbar bone mineral density, bone turnover, and lipid metabolism in elderly women with osteoporosis. Yonsei Med J. 29 2008;49(1):119-128.

32. Gorai I, Hattori S, Tanaka Y, Iwaoki Y. Alfacalcidol-supplemented raloxifene therapy has greater bone-sparing effect than raloxifenealone therapy in postmenopausal Japanese women with osteoporosis or osteopenia. J Bone Miner Metab. 2012;30(3):349-358.

33. Majima T, Komatsu Y, Shimatsu A, et al. Efficacy of combined treatment with raloxifene and alfacalcidol on bone density and biochemical markers of bone turnover in postmenopausal osteoporosis. Endocr J. 2008;55(1):127-134.

34. Hayashi T, Ina K, Maeda M, Nomura H. The effects of selective estrogen receptor modulator treatment following hormone replacement therapy on elderly postmenopausal women with osteoporosis. Nitric Oxide. 2011;24(4):199-203.

35. Morii H, Ohashi Y, Taketani Y, et al. Effect of raloxifene on bone mineral density and biochemical markers of bone turnover in Japanese postmenopausal women with osteoporosis: results from a randomized placebo-controlled trial. Osteoporos Int. 2003;14(10):793-800. 
36. Majima T, Komatsu Y, Shimatsu A, et al. Clinical significance of 1-year treatment with raloxifene on bone and lipid metabolism in Japanese postmenopausal women with osteoporosis. Endocr J. 2007;54(6):855-862.

37. Majima T, Shimatsu A, Komatsu Y, et al. Association between baseline values of bone turnover markers and bone mineral density and their response to raloxifene treatment in Japanese postmenopausal women with osteoporosis. Endocr J. 2008b;55(1):41-48.

38. Majima T, Shimatsu A, Satoh N, et al. Three-month changes in bone turnover markers and bone mineral density response to raloxifene in Japanese postmenopausal women with osteoporosis. $J$ Bone Miner Metab. 2008;26(2):178-184.

39. Takada J, Iba K, Yoshizaki T, Yamashita T. Correlation between a bone resorption marker and structural geometry of the proximal femur in osteoporotic women treated with raloxifene. J Orthop Surg (Hong Kong). 2012;20(2):209-213.

40. Iikuni N, Hamaya E, Nihojima S, et al. Safety and effectiveness profile of raloxifene in long-term, prospective, postmarketing surveillance. J Bone Miner Metab. 2012;30(6):674-682.

41. Urushihara H, Kikuchi N, Yamada M, Yoshiki F, Miyauchi A. Raloxifene and stroke risks in Japanese postmenopausal women with osteoporosis on postmarketing surveillance. Menopause. 2009;16(5):971-977.

42. Yoh K, Hamaya E, Urushihara H, et al. Quality of life in raloxifenetreated Japanese women with postmenopausal osteoporosis: a prospective, postmarketing observational study. Curr Med Res Opin. 2012;28(11):1757-1766.

43. Orimo H, Hayashi Y, Fukunaga M, et al. Diagnostic criteria for primary osteoporosis: year 2000 revision. J Bone Miner Metab. 2001; 19(6):331-337.

44. Eli Lilly Japan. Evista [package insert]. Kobe, Japan: Eli Lilly Japan; 2007.

45. Dutertre M, Smith CL. Molecular mechanisms of selective estrogen receptor modulator (SERM) action. J Pharmacol Exp Ther. 2000; 295(2):431-437.

46. Ettinger B, Black DM, Mitlak BH, et al. Reduction of vertebral fracture risk in postmenopausal women with osteoporosis treated with raloxifene: results from a 3-year randomized clinical trial. Multiple Outcomes of Raloxifene Evaluation (MORE) Investigators. JAMA. 1999;282(7):637-645.

47. Delmas PD, Ensrud KE, Adachi JD, et al. Efficacy of raloxifene on vertebral fracture risk reduction in postmenopausal women with osteoporosis: four-year results from a randomized clinical trial. J Clin Endocrinol Metab. 2002;87(8):3609-3617.

48. Qu Y, Wong M, Thiebaud D, Stock JL. The effect of raloxifene therapy on the risk of new clinical vertebral fractures at three and six months: a secondary analysis of the MORE trial. Curr Med Res Opin. 2005;21(12): 1955-1959.

49. Kikuchi T. [Effect of combination therapy with eldecalcitol and raloxifene on bone metabolism in osteoporotic patients]. Ther Res. 2012;33(9):1423-1429. Japanese.

50. Takeda S, Sakai S, Shiraishi A, Koike N, Mihara M, Endo K. Combination treatment with eldecalcitol (ED-71) and raloxifene improves bone mechanical strength by suppressing bone turnover and increasing bone mineral density in ovariectomized rats. Bone. 2013;53(1):167-173.

51. Kanis JA, Johnell O, Oden A, et al. The risk and burden of vertebral fractures in Sweden. Osteoporos Int. 2004;15(1):20-26.

52. Ross PD, Fujiwara S, Huang C, et al. Vertebral fracture prevalence in women in Hiroshima compared to Caucasians or Japanese in the US. Int J Epidemiol. 1995;24(6):1171-1177.

53. Kwok AW, Leung JC, Chan AY, et al. Prevalence of vertebral fracture in Asian men and women: comparison between Hong Kong, Thailand, Indonesia and Japan. Public Health. 2012;126(6):523-531.

54. Ito M, Nishida A, Uetani M, Hayashi K. Osteoporosis in the Japanese population. Semin Musculoskelet Radiol. 2001;5(2):121-126.
55. Centers for Disease Control and Prevention. Osteoporosis. Available from: http://www.cdc.gov/nchs/data/nhanes/databriefs/osteoporosis. pdf. Accessed June 14, 2013.

56. Huang C, Ross PD, Fujiwara S, et al. Determinants of vertebral fracture prevalence among native Japanese women and women of Japanese descent living in Hawaii. Bone. 1996;18(5):437-442.

57. Morita A. [Genetic factors of osteoporosis and fracture and the application of genetic information to the preventive medicine]. Clin Calcium. 2005;15(8):1364-1371. Japanese.

58. Masaki H, Miki T. [Bone and calcium metabolism in elderly women]. Clin Calcium. 2011;21(9):1361-1367. Japanese.

59. Nakamura K, Kurahashi N, Ishihara J, Inoue M, Tsugane S. Calcium intake and the 10-year incidence of self-reported vertebral fractures in women and men: the Japan Public Health Centre-based Prospective Study. Br J Nutr. 2009;101(2):285-294.

60. Ohishi H, Nakamura Y, Kishiya M, Toh S. Spontaneous femoral neck fracture associated with a low serum level of vitamin D. J Orthop Sci. 2013;18(3):496-499.

61. Fujiwara S, Hamaya E, Goto W, et al. Vertebral fracture status and the World Health Organization risk factors for predicting osteoporotic fracture risk in Japan. Bone. 2011;49(3):520-525.

62. Beck TJ, Ruff CB, Warden KE, Scott WW Jr, Rao GU. Predicting femoral neck strength from bone mineral data. A structural approach. Invest Radiol. 1990;25(1):6-18

63. Beck TJ, Looker AC, Ruff CB, Sievanen H, Wahner HW. Structural trends in the aging femoral neck and proximal shaft: analysis of the Third National Health and Nutrition Examination Survey dual-energy X-ray absorptiometry data. J Bone Miner Res. 2000;15(12):2297-2304.

64. Beck TJ, Ruff CB, Bissessur K. Age-related changes in female femoral neck geometry: implications for bone strength. Calcif Tissue Int. 1993;53 Suppl 1:S41-S46.

65. Beck TJ, Ruff CB, Scott WW Jr, Plato CC, Tobin JD, Quan CA. Sex differences in geometry of the femoral neck with aging: a structural analysis of bone mineral data. Calcif Tissue Int. 1992;50(1):24-29.

66. Takada J, Beck TJ, Iba K, Yamashita T. Structural trends in the aging proximal femur in Japanese postmenopausal women. Bone. 2007;41(1):97-102.

67. Wang XF, Duan Y, Beck TJ, Seeman E. Varying contributions of growth and ageing to racial and sex differences in femoral neck structure and strength in old age. Bone. 2005;36(6):978-986.

68. Beck TJ, Lewiecki EM, Miller PD, et al. Effects of denosumab on the geometry of the proximal femur in postmenopausal women in comparison with alendronate. J Clin Densitom. 2008;11(3):351-359.

69. Bonnick SL, Beck TJ, Cosman F, Hochberg MC, Wang H, de Papp AE. DXA-based hip structural analysis of once-weekly bisphosphonatetreated postmenopausal women with low bone mass. Osteoporos Int. 2009;20(6):911-921.

70. Greenspan SL, Wyman A, Hooven FH, et al. Predictors of treatment with osteoporosis medications after recent fragility fractures in a multinational cohort of postmenopausal women. J Am Geriatr Soc. 2012;60(3):455-461.

71. Uusi-Rasi K, Semanick LM, Zanchetta JR, et al. Effects of teriparatide [rhPTH (1-34)] treatment on structural geometry of the proximal femur in elderly osteoporotic women. Bone. 2005;36(6):948-958.

72. Grady D, Ettinger B, Moscarelli E, et al. Safety and adverse effects associated with raloxifene: multiple outcomes of raloxifene evaluation. Obstet Gynecol. 2004;104(4):837-844.

73. Kamibayashi J. Current State of Therapy for Deep Venous Thrombosis and Pulmonary Embolism at Special Centers in Japan. Study Report 55-58. Tokyo: Abnormal Blood Coagulation Study Group, Ministry of Health, Labour and Welfare, Japan; 1995.

74. Hamaya E, Sowa H. Re: Raloxifene and stroke risks in Japanese postmenopausal women with osteoporosis on postmarketing surveillance. Menopause. 2014;21(1):109-110. 
75. Barrett-Connor E, Mosca L, Collins P, et al. Effects of raloxifene on cardiovascular events and breast cancer in postmenopausal women. N Engl J Med. 2006;355(2):125-137.

76. Masunari N, Fujiwara S, Nakata Y, Nakashima E, Nakamura T. Historical height loss, vertebral deformity, and health-related quality of life in Hiroshima cohort study. Osteoporos Int. 2007;18(11):1493-1499.
77. Hagino H, Nakamura T, Fujiwara S, Oeki M, Okano T, Teshima R. Sequential change in quality of life for patients with incident clinical fractures: a prospective study. Osteoporos Int. 2009;20(5):695-702.

78. Iba K, Takada J, Hatakeyama N, et al. Underutilization of antiosteoporotic drugs by orthopedic surgeons for prevention of a secondary osteoporotic fracture. J Orthop Sci. 2006;11(5):446-449.

\section{Publish your work in this journal}

Clinical Interventions in Aging is an international, peer-reviewed journal focusing on evidence-based reports on the value or lack thereof of treatments intended to prevent or delay the onset of maladaptive correlates of aging in human beings. This journal is indexed on PubMed Central, MedLine,

\section{Dovepress}

CAS, Scopus and the Elsevier Bibliographic databases. The manuscript management system is completely online and includes a very quick and fair peer-review system, which is all easy to use. Visit http://www.dovepress. $\mathrm{com} /$ testimonials.php to read real quotes from published authors. 